Article

\title{
Evaluation of the Cooling and Pavement Performance of Basic Oxygen Furnace Slag Used in Asphalt Mixture
}

\author{
Long-Sheng Huang \\ Department of Distribution Management, SHU-TE, Kaohsiung City 82445, Taiwan; sheng@stu.edu.tw; \\ Tel.: +886-7-615-8000 (ext. 2203)
}

Received: 15 September 2017; Accepted: 14 November 2017; Published: 27 November 2017

\begin{abstract}
Basic oxygen furnace slag (BOF) is widely used in road construction, but there is a lack of characteristics in different asphalt mixtures. This study investigates the properties of hot-mixed asphalt (HMA), containing stone mastic asphalt (SMA), porous asphalt (PA), and dense-graded BOF as a partial substitution for natural aggregates. The purpose of this study is to evaluate various BOF slag contents in the asphalt mixtures that would affect the cooling behavior after compaction. Asphalt mixture specimens contained $0 \%, 20 \%, 40 \%$ and $60 \%$ BOF slag, respectively, as coarse aggregate. Test results showed that BOF slag has a lipophilic property, so that it can be adsorbed by asphalt cement, thereby reducing the cost of asphalt. The stability value of all the asphalt mixtures increases with the proportion of BOF slag replacement. In addition, the voids in the mineral aggregate (VMA) value variable exhibited significant differences among asphalt mixtures, and could determine the deviation of the cooling trend of asphalt mixtures. Furthermore, it was found that the cooling procedure of the BOF slag used in dense-graded asphalt mixture takes about $100 \mathrm{~min}$, and that the temperature tends to be moderate; however, it took about $120 \mathrm{~min}$ of cooling the SMA and PA mixture with BOF slag. In addition, the distribution of voids of the dense asphalt mixture was not uniform. This would result in various locations of inconsistent thermal energy temperature on asphalt mixtures.
\end{abstract}

Keywords: asphalt mixture; cooling; basic oxygen furnaces (BOF) slag

\section{Introduction}

Basic oxygen furnace slag (BOF) is a steelmaking by-product. China's annual output of BOF slag reaches 2 million tons [1], and most of the BOF slag treatment methods involve conveyance to a disposal site for landfill which consumes space; as well, water osmosis from BOF slag causes environmental pollution. There have been several studies on the feasibility of employing other applications. Rockliff and Moffett 2002 [2] pointed out that BOF slag has similar properties to natural aggregate, and has no any compromising effects on asphalt cement. Xue et al. 2006 [3] investigated the applications of BOF for coarse aggregate asphalt mixture, which showed a better construction performance than natural aggregate. In addition, BOF slag can be applied to road construction. BOF slag has a coarser surface texture than that of the conventional aggregate; the adhesive force between BOF slag and asphalt binder improved the asphalt mixture. Xie et al. 2012 [4] used a freeze-thaw experiment to compare reused BOF asphalt mixture, and found that it still had better resistance to water sensitivity when compared to basalt aggregate.

In order to improve the performance of asphalt pavement, various laboratory tests have been used to evaluate the feasibility at different conditions. Stone mastic asphalt (SMA) has a high stone content, which forms a gap-graded skeleton-like stone structure. It provides deformation resistance and durability, making it suitable for heavily trafficked roads. The voids of the mixture's structure 
are filled with a high asphalt mastic and filler. The stone skeleton of SMA has a high angularity that improves the interlocking packing and stone-on-stone contact among aggregates $[5,6]$. Porous asphalt (PA) has crushed coarse aggregate without a significant proportion of fine aggregate, and it has high drainage and noise-abrasion properties. The performance of PA mixtures regarding rutting resistance and moisture susceptibility is not as efficient as that of dense graded mixture [7,8]. In addition, reclaimed asphalt pavement (RAP) is a useful alternative to virgin materials because it reduces the need to use virgin aggregate [9]. However, Pratico 2004 [10] showed that the hardness of the total asphalt cement in the mixture increases with the RAP content, while rejuvenating agents were added to the mixture in order to improve the recovered binder performance.

Based on the excellent performance of SMA and PA mixtures, many studies used BOF slag as aggregate in SMA and PA mixtures. Shen et al. 2009 [11] added BOF into a porous asphalt (PA) mixture, and found that BOF could improve the skid resistance, water sensitivity, rutting resistance, and sound absorptivity. When used for BOF slag stone mastic asphalt (SMA) mixtures, BOF slag presents high rutting resistance, high-temperature stability, and resistance of moisture damage to improve the stability of high-temperature permanent deformation and low-temperature brittleness, effectively increasing the stability of mixtures [12,13]. Wu et al. 2007 [14] indicated that BOF slag could be characterized as a porous material and could improve the absorption of the asphalt binder in asphalt mixture. The permanent deformation produced at elevated temperatures for asphalt pavement was reduced.

In addition, a newly rehabilitated asphalt pavement has been compacted, and a period of time is required for the mixture to gain strength. The pavement could open to traffic only after it has been cooled and achieved adequate strength $[15,16]$. Criteria for opening pavements to traffic have generally been based on time or strength. Huang and Lin 2011 [17] investigated the thermal temperature effect of BOF slag substituted in a reclaimed asphalt mixture, and found that BOF slag could decrease the cooling effect, which means that BOF slag mixture has a temperature preservation effect.

However, few studies have been conducted on the cooling effect of different aggregate gradation on asphalt mixtures, and substantiating the 'open to traffic' criterion. Thus, this study evaluated BOF slag applications to different aggregate gradations of asphalt mixtures, including the dense, SMA, and PA graded. This study also analyzed the basic properties and cooling properties of BOF slag that is used in asphalt mixtures, and evaluated BOF slag applications regarding the effectiveness of stabilization and 'open to traffic' time of different types of aggregate gradation asphalt mixtures. The objectives of this research are listed as follows:

- estimating the cooling effect of BOF slag substitution used in dense, SMA and PA mixtures;

- comparing the cooling interval of different aggregate gradations on asphalt mixtures;

- evaluating the reasonable 'open to traffic' temperature of BOF slag substitution used in different asphalt mixtures; and,

- $\quad$ observing the voids distribution of BOF slag substitution used in different asphalt mixtures.

\section{Materials and Method}

\subsection{Basic Properties of Asphalt and Aggregate}

The BOF slag used in this study originated from the steelmaking furnace areas of the China Steel Corporation (Taiwan); the virgin aggregates (granite) were provided from a local asphalt plant. The BOF slag was used as the substitute of coarse aggregate. The physical properties of BOF slag and virgin aggregate are listed in Table 1 . The apparent specific gravity of natural aggregate and BOF slag is shown in Sections 2.2 and 3.3, respectively. BOF slag is a by-product that is generated during the steelmaking process; therefore, it contains a higher amount of iron, resulting in higher specific gravity and improved load-bearing capacity. In addition, the test results indicated that BOF slag has higher water absorption, but lower Los Angeles (L.A.) abrasion and flat and elongated (F \& E) ratio than natural aggregate. 
Table 1. The basic oxygen furnace slag (BOF) slag and natural aggregate properties.

\begin{tabular}{ccccc}
\hline & BOF Slag & $\begin{array}{c}\text { Natural Coarse } \\
\text { Aggregate }\end{array}$ & Criteria & Specification \\
\hline Apparent specific gravity & 3.17 & 2.60 & - & ASTM C127-07 [18] \\
Water absorption $(\%)$ & 2.60 & 1.69 & 3 & ASTM C127-07 \\
Los Angeles abrasion test $(\%)$ & 11.30 & 28.89 & 40 & AASHTO T96 [19] \\
Fracture $(\leq 3 \%)$ & 2.64 & 22.24 & - & ASTM D5821-01 [20] \\
Surface $(\geqq 3 \%)$ & 96.30 & 78.80 & - & ASTM D5821-01 \\
Flat and elongated ratio $(\mathrm{F} \& \mathrm{E})(\geqq 1: 3 \%)$ & 0.91 & 6.88 & 7 & ASTM D4791-10 [21] \\
\hline
\end{tabular}

The flatness ratios of BOF slag and natural aggregate are 0.91 and 6.88 , respectively. The flatness ratio is defined as the ratio between the flat and elongated sides of coarse aggregate particles, and as the indicator of the load-bearing capacity for the asphalt mixture. The larger flatness ratio means that the aggregate may break and result in a decreased loading resistance. These characteristics would provide more aggregate interlocking and increase the resistance to aggregate breakdown by heavy vehicles. AC-20 grade cement is used for the asphalt binder. The basic properties of asphalt cement are shown in Table 2.

Table 2. The asphalt binder properties.

\begin{tabular}{cccc}
\hline Test & Results & Criteria & Specification \\
\hline Specific gravity & 1.037 & - & AASHTO T228 [22] \\
Softening point $\left({ }^{\circ} \mathrm{C}\right)$ & 57 & 50 & AASHTO T36 [23] \\
Ductility $\left(25^{\circ} \mathrm{C}, 5 \mathrm{~cm} / \mathrm{min}, \mathrm{cm}\right)$ & $100+$ & 50 & AASHTO T51 [24] \\
Flash point $\left({ }^{\circ} \mathrm{C}\right)$ & $230+$ & 232 & AASHTO T48 [25] \\
Viscosity $\left(60{ }^{\circ} \mathrm{C}\right.$, poise $)$ & 1665 & $2000 \pm 400$ & AASHTO M226 [26] \\
Solubility $(\%)$ & 99.5 & 99 & AASHTO T44 [27] \\
Mix temperature $\left(170 \pm 20 \mathrm{cSt},{ }^{\circ} \mathrm{C}\right)$ & 155 & - & ASTM D2493 [28] \\
Compaction temperature $\left(280 \pm 30 \mathrm{cSt},{ }^{\circ} \mathrm{C}\right)$ & 143 & - & ASTM D2493 \\
Penetration $\left(25^{\circ} \mathrm{C}, 100 \mathrm{~g}, 5 \mathrm{~s} 0.1 \mathrm{~mm}\right)$ & 68.7 & 60 & AASHTO M20 [29] \\
\hline
\end{tabular}

\subsection{Asphalt Specimen Preparation}

The asphalt mix design was based on the Marshall Mix design method to incorporate the use of natural and BOF slag aggregates. The optimum asphalt contents in various asphalt mixtures (dense, SMA, and PA) were determined in accordance to the Asphalt Institute method, MS-2 [30]. Three samples for each mixture was made at $4.5 \%, 5.0 \%, 5.5 \%, 6.0 \%$ and $6.5 \%$ asphalt by dry weight for a total of 15 samples. In addition, the viscosity blending chart was utilized to determine the binding and compaction temperature of the asphalt mixtures.

The 15 samples were then heated to $120^{\circ} \mathrm{C}$ to simulate the asphalt mix temperature during asphalt paving. In this study, the viscosity blending chart was employed to determine the optimum blend and compaction temperature of the new asphalt binder. Asphalt samples were also prepared for Marshall Mix testing at a blend temperature of $120^{\circ} \mathrm{C}$ and a compaction temperature of $115^{\circ} \mathrm{C}$.

The purpose of using the Marshall Mix design is to ensure that the proportion distribution of each volume of aggregate in the asphalt mixture can comply with the standards specifications of designed gradation. Marshall Mix design mainly measures different property parameters of asphalt content, such as asphalt mixture stability value, flow value, unit weight, air void (VA), VFA (voids filled with asphalt), and VMA (voids in the mineral aggregate), to determine the optimum asphalt content for all mixtures.

The BOF slag was used to substitute portions of the coarse aggregate, while virgin fine aggregate was applied. The percentages of the BOF slag used were $0 \%, 20 \%, 40 \%$ and $60 \%$ by volume of coarse aggregate, which corresponded to $0 \%, 12 \%, 27 \%$ and $42 \%$ of total aggregate by volume, correspondingly.

This study adopted AC-20 grade asphalt cement as the binder and mixed BOF slag with dense SMA and PA-graded, respectively; as well, the additive volume of coarse aggregate was set in the 
following ratios: $20 \%, 40 \%$ and $60 \%$, and the test results of sieve analysis are shown in Tables $3-5$. The nominal maximum size for each aggregate is $19 \mathrm{~mm}$. In order to effectively compare every property of the asphalt mixture, all aggregate gradation distributions are centralized within the range of one times the standard deviation for the intermediate interval.

Table 3. Sieve distribution (dense-graded mixture).

\begin{tabular}{cccccc}
\hline \multirow{2}{*}{ Sieve (mm) } & \multicolumn{5}{c}{ BOF Replacement (\%) } \\
\cline { 2 - 6 } & $\mathbf{0}$ & $\mathbf{2 0}$ & $\mathbf{4 0}$ & $\mathbf{6 0}$ & Criteria \\
\hline 25 & 100 & 100 & 100 & 100 & 100 \\
19 & 98.1 & 98.2 & 99.0 & 99.0 & $80-100$ \\
12.5 & 79.4 & 82.8 & 94.2 & 93.8 & - \\
9.5 & 73.9 & 74.1 & 77.9 & 75.7 & $60-80$ \\
4.75 & 58.1 & 63.4 & 60.9 & 48.4 & $48-65$ \\
2.36 & 41.0 & 50.0 & 49.7 & 35.5 & $35-50$ \\
1.18 & 31.6 & 39.3 & 39.4 & 27.8 & - \\
0.6 & 23.7 & 29.3 & 29.5 & 21.2 & $19-30$ \\
0.3 & 16.4 & 20.0 & 20.2 & 14.9 & $13-23$ \\
0.15 & 9.8 & 11.5 & 11.6 & 9 & $7-15$ \\
0.075 & 6.0 & 6.6 & 6.6 & 5.3 & $0-8$ \\
\hline
\end{tabular}

Table 4. Sieve distribution (stone mastic asphalt (SMA)-graded mixture).

\begin{tabular}{cccccc}
\hline \multirow{2}{*}{ Sieve (mm) } & \multicolumn{5}{c}{ BOF Replacement (\%) } \\
\cline { 2 - 6 } & $\mathbf{0}$ & $\mathbf{2 0}$ & $\mathbf{4 0}$ & $\mathbf{6 0}$ & Criteria \\
\hline 25 & 100 & 100 & 100 & 100 & 100 \\
19 & 97.9 & 93.9 & 99.7 & 99.0 & $90-100$ \\
12.5 & 77.0 & 44.4 & 95.7 & 94.4 & - \\
9.5 & 72.0 & 38.0 & 78.3 & 79.6 & $56-80$ \\
4.75 & 58.1 & 27.4 & 54.2 & 51.2 & $35-65$ \\
2.36 & 39.2 & 20.1 & 33.0 & 36.1 & $23-49$ \\
1.18 & 29.5 & 17.5 & 24.2 & 28.2 & - \\
0.6 & 21.9 & 15.5 & 18.4 & 21.5 & - \\
0.3 & 15.0 & 13.7 & 13.3 & 15.1 & $5-19$ \\
0.15 & 8.6 & 12.0 & 8.7 & 9.2 & - \\
0.075 & 5.0 & 10.6 & 5.8 & 5.4 & $2-8$ \\
\hline
\end{tabular}

Table 5. Sieve distribution (porous asphalt (PA)-graded mixture).

\begin{tabular}{cccccc}
\hline \multirow{2}{*}{ Sieve (mm) } & \multicolumn{5}{c}{ BOF Replacement (\%) } \\
\cline { 2 - 6 } & $\mathbf{0}$ & $\mathbf{2 0}$ & $\mathbf{4 0}$ & $\mathbf{6 0}$ & Criteria \\
\hline 25 & 100 & 100 & 100 & 100 & 100 \\
19 & 97.2 & 97.3 & 97.6 & 97.8 & $95-100$ \\
12.5 & 68.4 & 69.2 & 71.1 & 73.4 & $64-84$ \\
9.5 & 56.9 & 54.7 & 51.1 & 53.4 & - \\
4.75 & 24.7 & 25.1 & 23.3 & 25.0 & $10-31$ \\
2.36 & 13.1 & 14.2 & 14.4 & 15.3 & $10-20$ \\
1.18 & 10.8 & 11.2 & 11.7 & 12.4 & - \\
0.6 & 8.9 & 8.9 & 9.8 & 10.5 & - \\
0.3 & 7.2 & 6.7 & 8.1 & 8.8 & - \\
0.15 & 5.6 & 4.7 & 6.4 & 7.1 & - \\
0.075 & 4.7 & 3.5 & 5.2 & 5.7 & $3-7$ \\
\hline
\end{tabular}

Since BOF slag is a substitute for coarse aggregate, and with the increased proportion of BOF slag, the passing percentage of coarse aggregate for every sieve will be decreased for the dense-graded mixtures. SMA and PA gradation would be formed to the jumping gradation (gap gradient) by 
increasing the coarse aggregate and replacement; therefore, with the increased proportion of BOF slag, the passing percentage of coarse aggregate for every sieve and replacement (\#200) will be reduced for both the SMA and PA mixtures.

\subsection{Laboratory Test Program}

\subsubsection{Cooling Measuring Test of Thermal Effect}

The cooling test was performed to evaluate the temperature variability on asphalt mixtures with different BOF slag contents. The surface of the actual pavement produced a heat convection effect with the atmosphere and the side of the pavement generated a circumference stress. Based on this, before measuring the cooling gradient of all specimens, it is necessary to prepare the simulated rutting specimen of asphalt mixtures, as shown in Figure 1. The purpose of this process is to simulate the actual pavement that has been completed after the rolling operation, and to assess the cooling behavior. In addition, the steel mode attached to both sides of the asphalt mixture specimen simulated the in situ pavement condition.

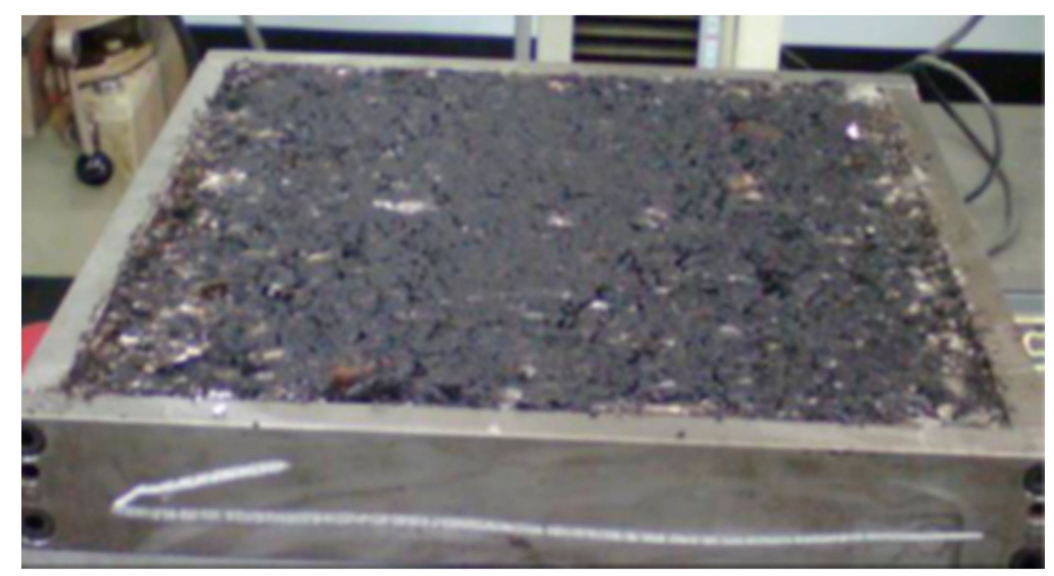

Figure 1. Rutting specimens for asphalt mixtures.

The wheel track test device was a British 77-B0350 type tester, a laboratory testing device that is designed to measure the rutting resistance of an asphalt mixtures. The conducted mold size was $30 \mathrm{~cm}$ in length $\times 30 \mathrm{~cm}$ in breadth $\times 5 \mathrm{~cm}$ in height; it was prepared and compacted in a steel mold. The size of the rubber block was $30 \times 30 \times 3.5 \mathrm{~cm}$. The stiffness value of the rubber block is close to the subgrade, and could simulate the reaction of the bottom layer by traffic loading [31].

The production process of the cooling test specimen involves putting the mixture into the mold and rolling by wheel tracking device testing. This device is commonly used for investigating the permanent performance of asphalt mixtures under conditions that simulate the effect of traffic and pavement temperature. The testing of samples within the wheel tracking device testing generally consisting of loading $0.5 \mathrm{MPa}$ were designed. Test specimens are tracked back and forth under the applied stationary loading. Testing is typically accomplished for a total of 8000 loading cycles (one cycle is defined as the backward and forward movement over samples by the wheel tracking device) [32]. All of the samples were then allowed to cool and the rate of cooling was measured and recorded.

\subsubsection{Thermal Imaging Measuring}

An infrared thermal imaging camera was simultaneously employed to measure the temperature pictures of the asphalt mixtures. This study measures the temperature variability of the surface layer of the specimen to estimate the heat convention between the asphalt specimen and the atmosphere during the cooling process. In addition, it was necessary to evaluate the cooling variability from the top to the bottom of the asphalt specimen. When an asphalt specimen has completed the compaction 
procedure, the side direction of the specimen mold was removed. The temperature variability in both the surface and side direction of the specimen were measured. Moreover, the specimen is placed in a confined space at room temperature and is maintained at $25^{\circ} \mathrm{C}$. This is intended to reduce the effect of atmospheric temperature on the cooling temperature of the test specimen. An infrared thermal imaging camera and thermal image transmission software were used to conduct the temperature monitoring and analyze the variation diagrams of the temperature distribution. The measurement equipment is shown in Figure 2. The temperature was recorded once every $5 \mathrm{~min}$ for a total of $180 \mathrm{~min}$, along with recording the temperature variation at the center and the surrounding points of the asphalt mixtures.

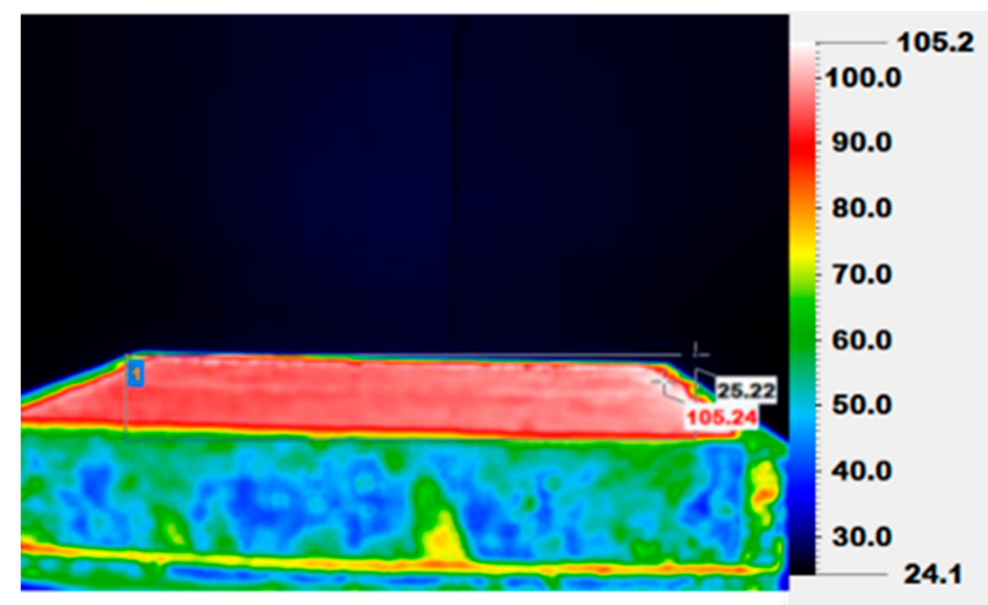

Figure 2. Thermal image of an asphalt mixture.

An infrared thermal imaging camera was employed to measure the temperature of the asphalt mixtures, together with thermal image analysis system application software. Based on a test scheme, continuous measurements of the temperature distribution and cooling gradient for designated points of different specimens are conducted at regular time intervals. Continuous measurements are made and recorded until the cooling temperature reaches room temperature. In addition, the procedure is also combined with the void structure distribution assessment of different asphalt specimens to observe the void structure, aggregate property, and temperature effect. Moreover, measurement temperature data were used to understand the heat preservation mechanism of BOF slag mixtures.

\section{Test Results and Discussions}

This study used the substitution ratio of BOF slag at $0 \%, 12 \%, 27 \%$ and $42 \%$ as coarse aggregate to substitute different aggregate gradation asphalt mixtures, with the time of dry mixing set at $15 \mathrm{~s}$ and $60 \mathrm{~s}$ for the wet mixing. The optimum asphalt content is determined from the average value of the corresponding asphalt contents to the maximum stability, the maximum unit weight, and $4 \%$ void rate, after calculating their optimum asphalt content, and creating the stability, with the test results being shown in Table 6.

\subsection{Optimum Asphalt Content}

The optimum asphalt content of the asphalt mixtures should provide a mix with sufficient asphalt film thickness to provide good durability and avoid excessive asphalt drainage. The optimum asphalt content is determined from the average value of the corresponding asphalt contents to the maximum stability, the maximum unit weight and $4 \%$ void rate. Higher asphalt content might lead to a poor bonding behavior for aggregate. However, a lower asphalt content of mixtures will potentially be susceptible to rutting and cracking. 
Optimum asphalt contents of dense, SMA, and PA-graded mixtures will be decreased when the BOF slag substituted proportion is increased. In BOF slag, the proportion of $\mathrm{SiO}_{2}$ is less than in natural gravel. However, $\mathrm{CaO}$ occupies a higher proportion [33,34]. Since $\mathrm{CaO}$ is lipophilic, and $\mathrm{BOF}$ slag structure has higher surface area and porosity, which facilitates absorption by the asphalt cement to allow for the aggregate to bond with the asphalt more tightly [13], and has proven BOF slag to be lipophilic, it can be easily absorbed and bond with asphalt cement. Chen et al. 2014 [35] undertook similar research, which used the boiling water test to demonstrate, after BOF slag contacted with asphalt cement, it will form hydration products and the bonding behavior of BOF slag and asphalt cement; therefore, it can decrease the asphalt content demand on asphalt mixtures.

SMA and PA-graded were designed as the jumping gradation with less proportion of fine aggregate and need to fill a large number of asphalt cement in voids among aggregates; but with the substitution of BOF slag for natural aggregate, it could lower the quantity demanded for asphalt cement, as well as reduce the cost of asphalt binder.

\subsection{Marshall Test Value}

The Marshall Test variable values for the three asphalt mixture gradients containing different BOF slag contents are shown in Table 6. In Table 6, the stability of dense, SMA, and PA-graded asphalt mixtures will be increased with the increasing BOF slag substitution ratio. The apparent specific gravity of the BOF slag is greater than the traditional aggregate and has a better load-bearing capacity; the asphalt film attached to the aggregate surface is also thicker.

Table 6. Marshall testing results of BOF mixtures.

\begin{tabular}{|c|c|c|c|c|c|c|c|c|}
\hline Gradient & BOF (\%) & $\begin{array}{l}\text { Optimum Asphalt } \\
\text { Content (\%) }\end{array}$ & $\begin{array}{c}\text { Unit } \\
\text { Weight }\end{array}$ & Air Voids (\%) & VMA & VFA & $\begin{array}{c}\text { Flow } \\
(0.25 \mathrm{~mm})\end{array}$ & $\begin{array}{l}\text { Stability } \\
(\mathrm{kN})\end{array}$ \\
\hline \multirow{4}{*}{ Dense } & 0 & 5.25 & 2.362 & 3.6 & 14.6 & 72.2 & 8.75 & 16.43 \\
\hline & 20 & 5.20 & 2.420 & 3.5 & 17.7 & 72.9 & 8.25 & 17.92 \\
\hline & 40 & 5.10 & 2.515 & 3.9 & 17.2 & 67.2 & 7.75 & 19.59 \\
\hline & 60 & 4.90 & 2.621 & 4.2 & 16.7 & 65.1 & 7.00 & 19.99 \\
\hline \multirow{4}{*}{ SMA } & 0 & 5.65 & 2.365 & 4.3 & 15.8 & 72.2 & 11.50 & 16.56 \\
\hline & 20 & 5.51 & 2.421 & 4.1 & 15.5 & 75.2 & 12.00 & 16.86 \\
\hline & 40 & 5.35 & 2.538 & 4.0 & 14.9 & 76.0 & 12.25 & 19.40 \\
\hline & 60 & 5.30 & 2.657 & 3.8 & 14.7 & 77.9 & 12.75 & 20.24 \\
\hline \multirow{4}{*}{$\mathrm{PA}$} & 0 & 5.95 & 2.382 & 4.6 & 17.8 & 72.5 & 12.00 & 16.46 \\
\hline & 20 & 5.82 & 2.430 & 4.3 & 17.5 & 74.1 & 12.50 & 16.95 \\
\hline & 40 & 5.53 & 2.556 & 4.1 & 16.8 & 76.0 & 13.25 & 20.24 \\
\hline & 60 & 5.41 & 2.727 & 3.7 & 15.8 & 81.1 & 13.50 & 20.43 \\
\hline Standard & & - & - & $3-5$ & $>13$ & - & $8-16$ & $>80$ \\
\hline
\end{tabular}

The stability of SMA and PA-graded asphalt mixtures is greater than that of the dense-graded ones. The stability of dense, SMA, and PA-graded mixtures were between 16.4 to $20 \mathrm{kN} ; 16.5$ to $20.2 \mathrm{kN}$; and, 16.4 to $20.4 \mathrm{kN}$, respectively. The stability of all the asphalt mixtures complies with the minimum requirement value of $80 \mathrm{kN}$.

The flow value of asphalt mixture decreases with the increase in the BOF slag substitution ratio; furthermore, if the flow value is too high, it means that permanent deformation may easily result for the pavement, possibly causing the phenomenon of plastic flow. However, the flow value of SMA and PA mixtures is much higher than that of the dense-graded mixture, which might indicate that the porosity of SMA and PA gradation lack the fine aggregate filled void among the aggregate. As well, the optimum amount of asphalt cement is high; thus, relative skidding may easily occur among aggregates, increasing the flow value.

The unit weight of the asphalt mixture will increase with the increased BOF slag substitution ratio. $\mathrm{BOF}$ aggregate contains $\mathrm{CaO}$, and its apparent specific gravity is greater than that of natural aggregate. Design coarse aggregate ratios of SMA and PA mixtures are more than that of the dense-graded 
mixture, and BOF slag was used to substitute for coarse aggregate; therefore, the unit weight of the asphalt mixture is obviously higher than that of the dense-graded one.

The void ratio is the ratio that is occupied by the void after mixing aggregate with an asphalt binder, and the specification is set at $3 \sim 5 \%$. The results showed that the void ratio of asphalt mixture decreased with the increased BOF slag substitution ratio. Since SMA and PA mixtures lack fine aggregate to fill the voids among aggregate particles, mixtures need more asphalt binder to achieve void replacement so as to comply with the specification set at $3-5 \%$ for the asphalt mixture void ratio. Nevertheless, since the apparent specific gravity between BOF slag and natural aggregate differs from each other, the compaction energy would cause aggregate fracture in the rolling process, making the gap-aggregate for gradation. As a result, the aggregate particles of dense-graded asphalt mixture might be rearranged, leading to the plastic flow or causing an increased void ratio for the asphalt mixture.

VMA is the occupation percentage of void in compacted aggregates without adding asphalt, and the standard specification is set at $13-14 \%$ as the minimum value. Rutting permanent may result if the value is less than the minimum value. The results showed that the asphalt mixture VMA value decreased with the increased BOF slag substitution ratio. The VMA value of the SMA-graded mixture is greater than that of the dense and PA-graded ones. BOF slag has porous properties, and asphalt cement can easily be permeated into the aggregate. Additionally, the traditional Marshall Mix Design method for the jumping gradation can easily increase the asphalt content; thus, the VMA values can be used to investigate whether or not the optimum amount of asphalt deviates from those of the others.

The VMA value of PA asphalt mixture without adding BOF slag is $17.8 \%$, while the VMA values for BOF substitution ratios $40 \%$ and $60 \%$ are $16.8 \%$ and $15.8 \%$, respectively. For the high-ratio mixture of BOF and aggregate, the VMA value decreased with the increased asphalt content. There might be relative skidding in SMA and PA-graded mixtures due to more asphalt binders.

Based on the Marshall testing results of BOF mixtures, it is indicated that the mechanism properties were increased with the increasing BOF slag substitution ratio for each asphalt mixture. An amount of $60 \%$ BOF slag substitution has the best engineering performance for each asphalt mixture. However, because the unit weight of BOF slag was greater than the natural aggregate, in order to avoid breakage and cause the degradation of aggregate during the mixing process, a BOF slag replacement of $60 \%$ was the optimum substitution for dense mixture. The replacement of $40 \%$ of BOF slag was the optimum substitution for SMA and PA mixtures.

\subsection{BOF Substitute Proportional Influence on Specimen Cooling}

Figure 3 shows the temperature variations at different BOF slag substitution ratios in the specimens. Since the specimen surfaces were in contact with the air, the temperature dropped quickly. All of the specimens have a maximum cooling gradient in the initial high-temperature status. As seen in Figure 3a, different amounts of BOF slag in dense-graded mixtures have a starting temperature of around $105-112{ }^{\circ} \mathrm{C}$. The temperatures at the surface decreased quickly, but stabilized after $80-90 \mathrm{~min}$. At the end of the measurements at $180 \mathrm{~min}$, the mixtures contained $20 \%$ of BOF slag had reached a stable condition at a temperature of $67^{\circ} \mathrm{C}$. However, for BOF slag at $40 \%$ and $60 \%$, the corresponding temperatures measured at $180 \mathrm{~min}$ were $69^{\circ} \mathrm{C}$ and $74^{\circ} \mathrm{C}$, respectively.

Since the specimen is placed in a confined indoor space and the control room temperature is about $25{ }^{\circ} \mathrm{C}$, the atmospheric temperature has only a slight effect on the cooling tendency among specimens. All of the specimens' temperatures at 0 minutes are different.

As seen in of Figure $3 b, c$, after SMA and PA-graded mixtures are cooled for $120 \mathrm{~min}$, the temperature tended to moderate, indicating that the heat-releasing effect of SMA and PA-graded mixtures tended to moderate, with heat preservation effectiveness. Additionally, the cooling rate of SMA and PA-graded mixtures decreased with the increased substitute proportion of BOF slag, which is similar to the cooling effect of adding BOF slag in dense-graded mixtures, and the cooling rate decreased significantly. Similar replacement proportions of $0 \%, 20 \%, 40 \%$ and $60 \%$ had the temperature when compared at $180 \mathrm{~min}$; where the temperatures of SMA gradation were $66^{\circ} \mathrm{C}, 69^{\circ} \mathrm{C}$, 
$70{ }^{\circ} \mathrm{C}$ and $73{ }^{\circ} \mathrm{C}$, respectively; the temperatures of the PA gradation were $68^{\circ} \mathrm{C}, 69^{\circ} \mathrm{C}, 70{ }^{\circ} \mathrm{C}$ and $74^{\circ} \mathrm{C}$, correspondingly.

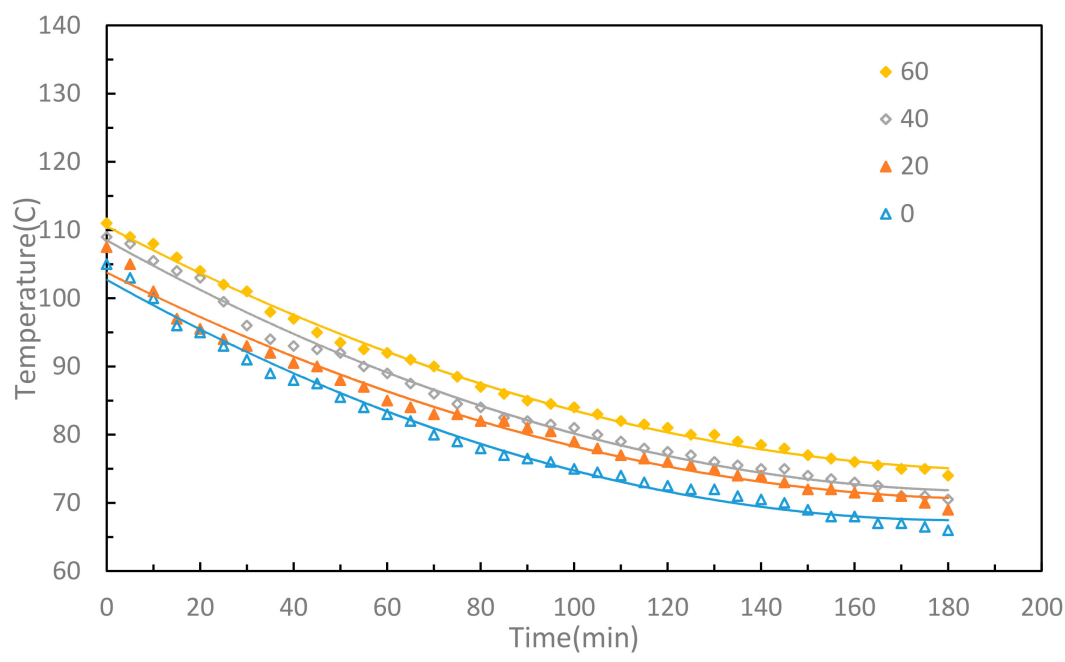

(a) Dense-graded mixture

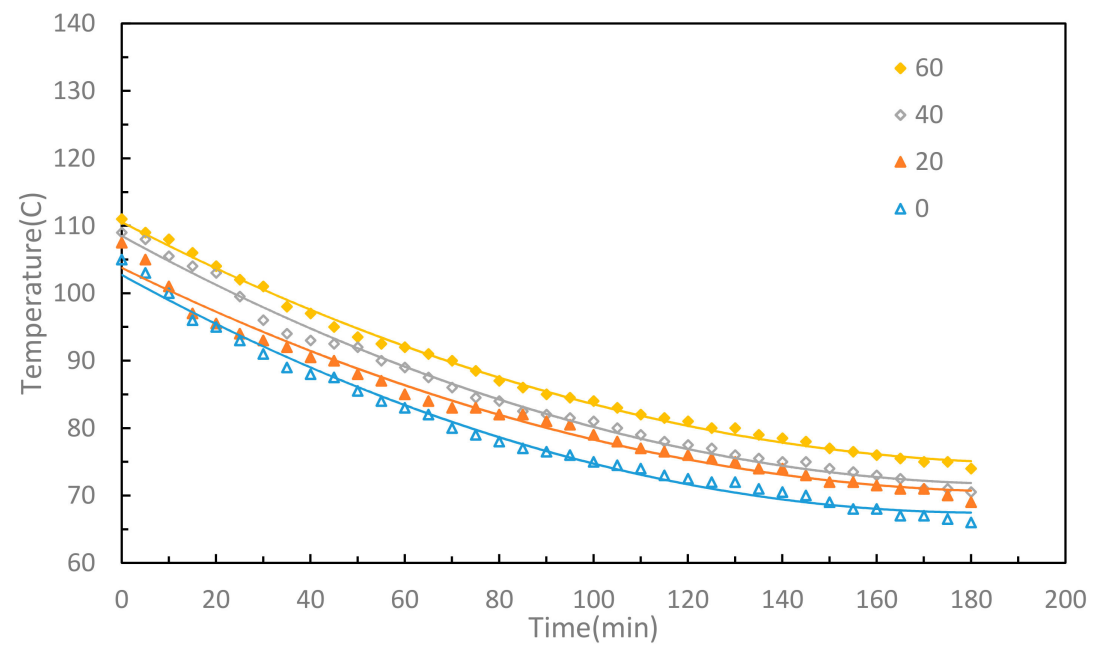

(b) SMA-graded mixture

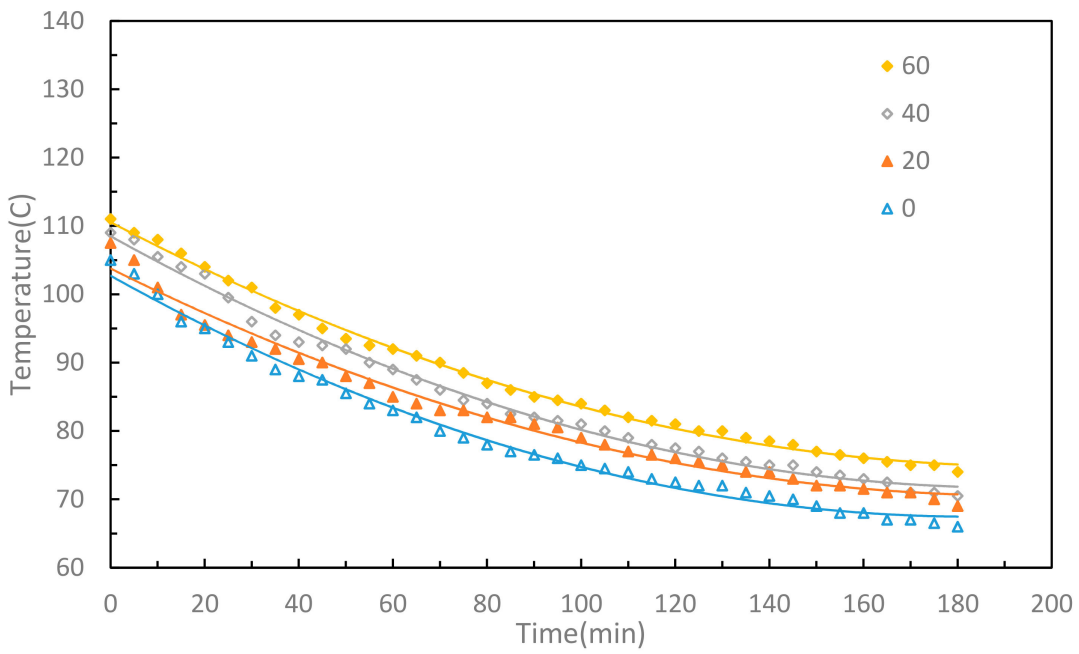

(c) PA-graded mixture

Figure 3. Temperature gradient variation diagram. 
After the compaction of asphalt specimens, the cooling temperature increased with the increased proportion of BOF slag, which means that besides having lipophilic qualities, BOF slag also has a heat preservation effect to maintain the temperature between aggregates, and facilitates the stable binding of asphalt with aggregate under sufficient temperature. The asphalt mixture used a high-proportion BOF aggregate; it needs to extend the heat to be released completely. The asphalt mixture can have highly stable properties. Furthermore, SMA and PA-graded mixtures are designed with a high proportion of coarse aggregate, and the aggregate skeleton is in direct contact between coarse aggregates to form the interlocking mechanism, as well as adding the high-proportion BOF as the coarse aggregate. Thus, the temperature can be preserved at the inter-contact status, and the cooling rate would be slow as well.

The purpose of this study was to estimate the cooling variable for each graded mixture and different BOF slag substitutions. Based on this, all of the specimens were placed in a confined space at room temperature and were maintained at $25{ }^{\circ} \mathrm{C}$. The effects of different graded mixtures and slag substitutions on the cooling effect for each specimen are much higher than the atmospheric temperature.

\subsection{The Effects of BOF Slag Contents on the Specimen Cooling Interval}

Huang and Lin (2011) established the three zones by the temperature-time curves: initial temperature, cessation temperature, and equilibrium temperature, respectively [17], as can be seen in Figure 4 . The initial temperature zone represents the temperature changes from the time the asphalt mixtures leave the plant to the end of the compaction. The mixtures reach a more stable state at the cessation temperature. In addition, the equilibrium temperature indicated that the asphalt temperature could basically be the proper time to be 'open to traffic'.

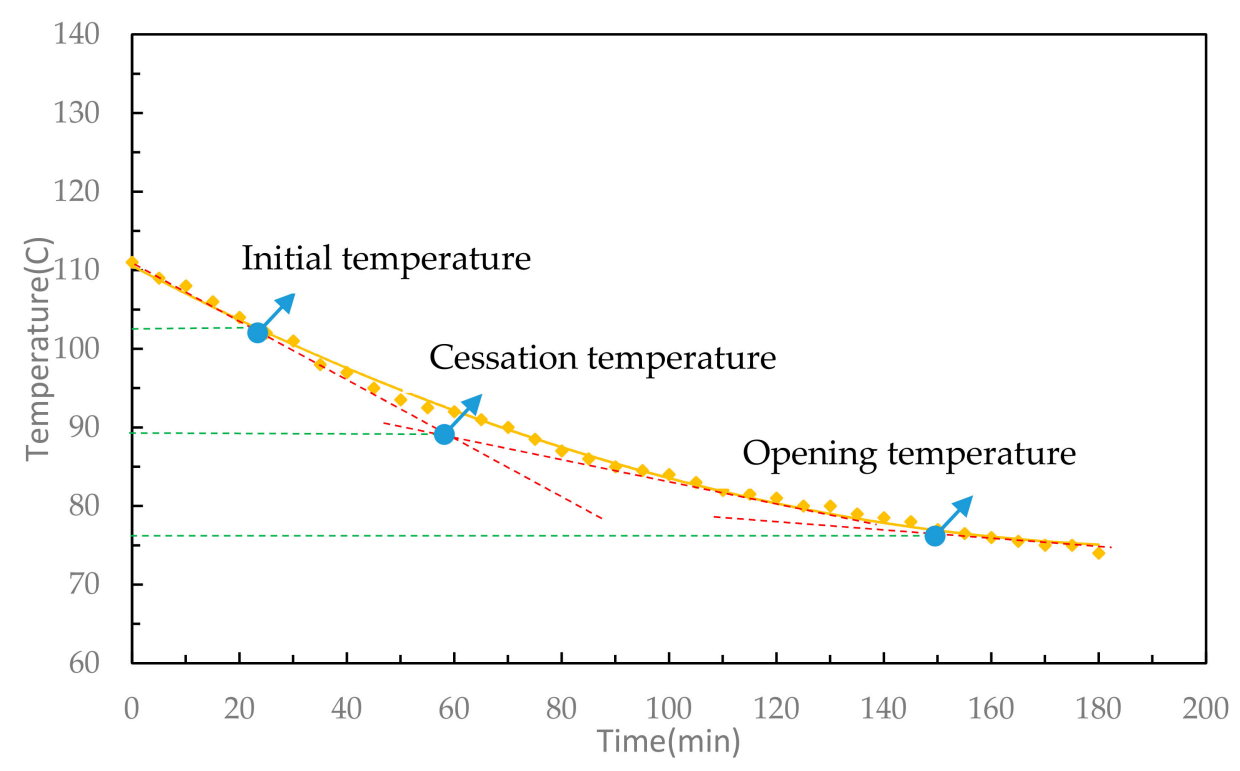

Figure 4. Cooling interval diagram of the asphalt mixture.

In this study, the temperature-time curves for mixtures containing various BOF slag content are shown in Figures 5-7. Temperatures corresponding to the three inflection points of the curve were defined as the points. From Figure 5, it can be seen that the initial temperature on dense mixtures decreases as the BOF slag content increases. For a dense specimen without BOF slag, the initial temperature was $95^{\circ} \mathrm{C}$; for a specimen with $60 \%$ BOF slag, the initial temperatures drops to $90{ }^{\circ} \mathrm{C}$. This means that the BOF slag in the dense mixtures can store the thermal energy longer. 


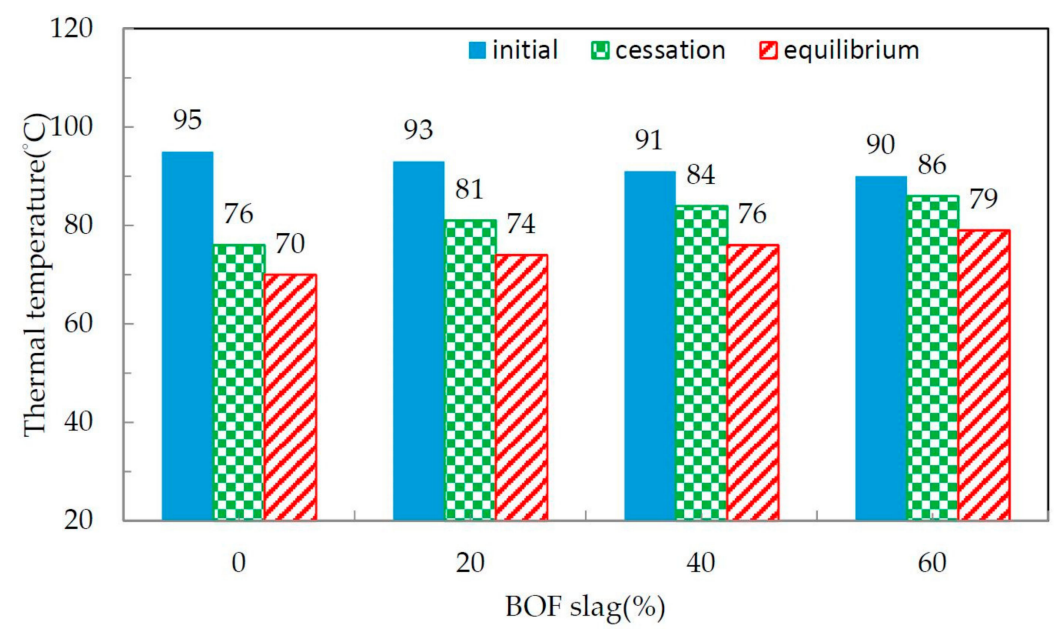

Figure 5. Relationship between the temperature intervals and the BOF slag contents (dense).

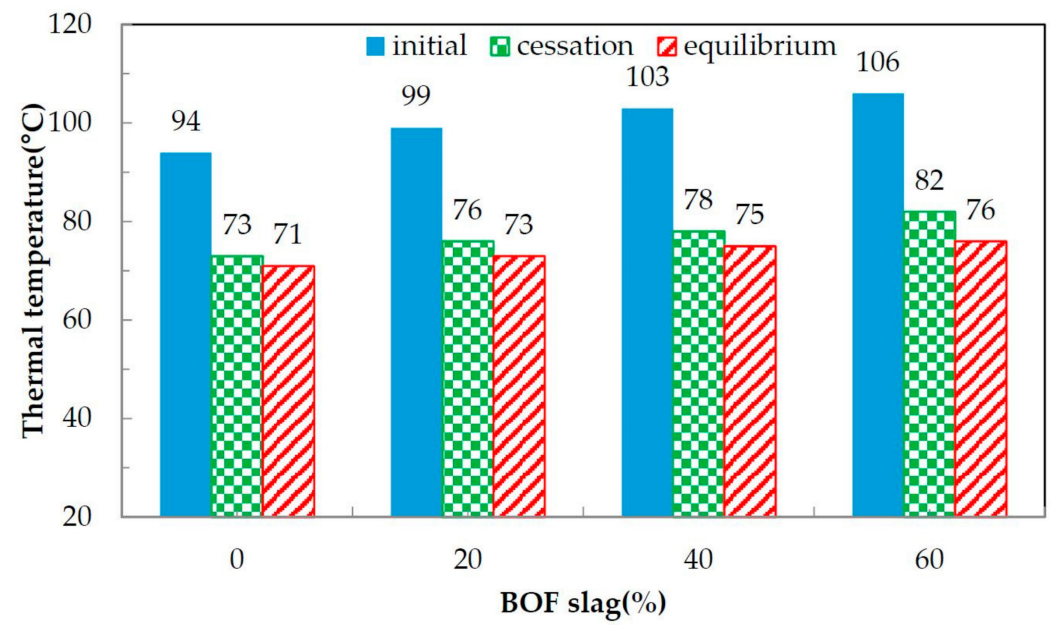

Figure 6. Relationship between the temperature intervals and the BOF slag contents (SMA).

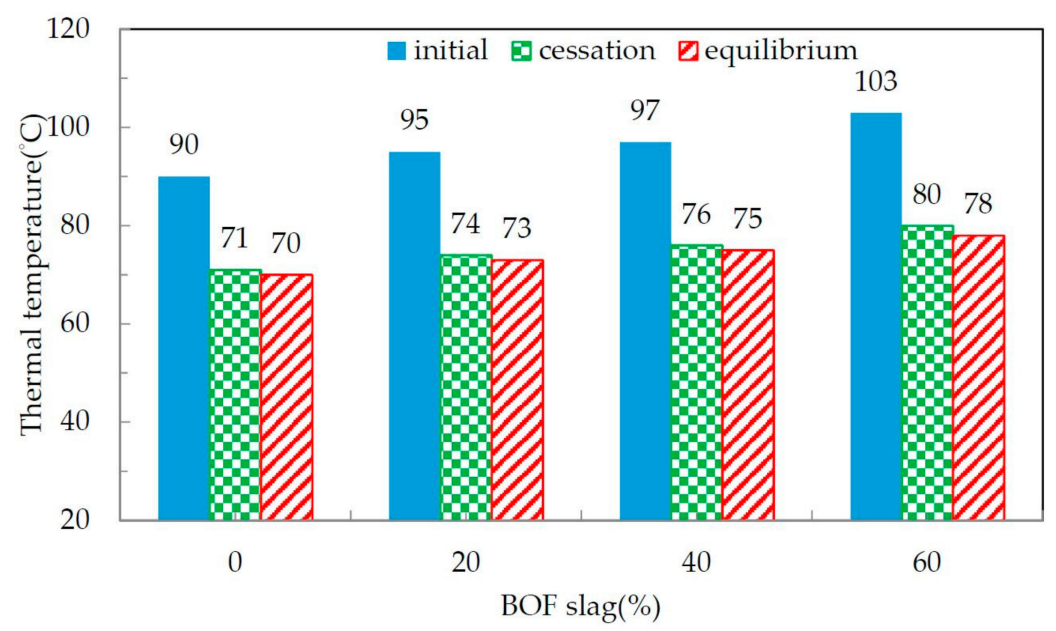

Figure 7. Relationship between the temperature intervals and the BOF slag contents (PA).

The cessation and equilibrium temperature increases as the BOF slag content increases. Willoughby et al. 2000 [37] defined the cessation temperature as the asphalt mixture temperature at which the density of asphalt pavement cannot be improved with additional compaction effort. Based 
on this concept, for mixtures without and with $100 \%$ BOF slag, the cessation temperatures drop to $76^{\circ} \mathrm{C}$ and $86^{\circ} \mathrm{C}$, respectively. The BOF slag in the dense mixtures could reach stability earlier at a higher temperature than those without BOF slag specimen. For mixtures without and with $60 \%$ BOF slag, the equilibrium temperature drops to $70^{\circ} \mathrm{C}$ and $79^{\circ} \mathrm{C}$, respectively. This phenomenon indicates that the use of $\mathrm{BOF}$ slag has a stable nature, even if the equilibrium temperature is higher than the pure, dense specimen, about $9{ }^{\circ} \mathrm{C}$, and it can be 'open to traffic' on asphalt pavement.

From Figure 6, the initial, cessation, and equilibrium temperature on SMA mixtures increase as the BOF slag content increases. The mixture, which is made with a high amount of the coarse particles, forms a coarse aggregate skeleton. This increases the interlocking of the aggregates and provides better stone-to-stone contact, which serves as a load carrying mechanism, and, hence, provides better loading resistance. SMA specimen coarse aggregate particles form a stone-to-stone contact skeleton that can transfer thermal energy and increase all of the temperature zones. Moreover, cessation and equilibrium temperatures of the SMA mixtures were not significantly different. This indicates that asphalt mixtures with BOF slag can be compacted and opening at higher temperatures as compared with those without BOF slag.

From Figure 7, the initial, cessation and equilibrium temperature on PA mixtures increase as the BOF slag content increases. A similar trend is also observed for the cooling interval within the SMA mixture. However, the PA mixture had a lower initial temperature interval than the SMA mixture. As mentioned earlier, for the mixtures with $40 \%$ and $60 \%$ of BOF slag, the VMA values of all the PA mixtures were higher than those of the SMA mixture, and, therefore, contain higher amounts of coarse aggregate $((19,12.5$ and $4.75 \mathrm{~mm}$ aggregate size $)$. Asphalt mixtures increase the porosity and contain a higher amount of coarse aggregate, which decreases the thermal conductivity, resulting in a higher temperature. A similar trend is also observed in the study results of Mohajerani et al. 2017 [38].

\subsection{Void Distribution of the Asphalt Mixture}

This study used infrared thermal imaging photos to prove the void distribution of the specimen by adding $40 \%$ BOF aggregate into three asphalt mixture gradations, for example, when comparing the cooling time at the 60th minute. As shown in Figure 8a, the dense mixture surface temperature image shows the center temperature of the specimen to be $91.7^{\circ} \mathrm{C}$; the temperature at the right side of the specimen is $94.8^{\circ} \mathrm{C}$. Since the heat exchange process would be transferred to the area with more voids, it is determined that the right side of the specimen may have more voids.

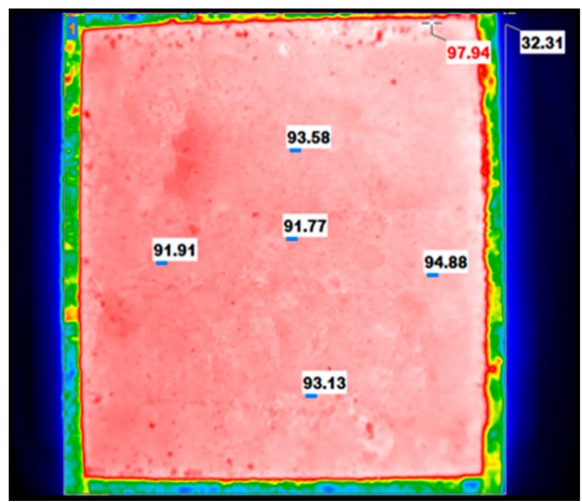

(a) Ortho thermal image

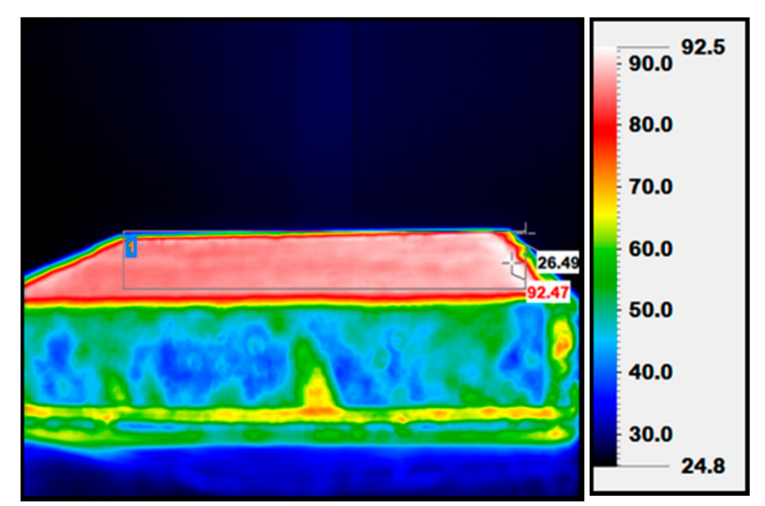

(b) Side thermal image

Figure 8. Dense-graded mixture thermal image $\left({ }^{\circ} \mathrm{C}\right)$.

Based on measuring of the surface and internal temperatures from the sides of the dense mixture, as shown in Figure $8 \mathrm{~b}$, it is found that the surface temperature of the specimen is about $92.4{ }^{\circ} \mathrm{C}$, and its internal temperature cooling rate is fast. The yellow area is about $60-70{ }^{\circ} \mathrm{C}$, which shows that after compacting the pavement in the cooling phase, the internal heat energy of asphalt mixture is 
continuously transferred upward; therefore, the surface temperature of pavement was higher than the internal one. In measuring the test results, as expected, for dense mixture, there was a significant difference between the internal and surface temperatures. Furthermore, from the thermal image, it can be determined that the distribution of voids of dense mixture is not uniform and the thermal energy temperature is inconsistent. This indicates that the non-uniform distribution of the voids on dense mixture caused the cooling process to decrease the loading resistance.

From Figure 9a, it can be found that the center temperature of the SMA specimen was $85.78^{\circ} \mathrm{C}$; those temperatures around the sides without any significant difference were about $85.16-85.98^{\circ} \mathrm{C}$, meaning that the internal void of the SMA mixture was more uniform than that of the dense mixture. The characteristic of the asphalt binder exhibits viscous-plastic behavior at a higher temperature. Thus, the film of the asphalt binder can be filled with voids during the high-temperature mixing process, and it would have smaller voids and heat energy that might not be easily dissipated. Observed from the side thermal image, as shown in Figure 9b, the SMA mixture heat can be transferred from the internal space up to the surface of the specimen. Since its internal voids are more uniform, its internal heat energy (yellow area) area occupied a larger range $\left(60-80^{\circ} \mathrm{C}\right)$; this showed that, in the cooling phase, the uniform void distribution can maintain the temperature with a slower heat dissipation rate than that of the dense mixture.

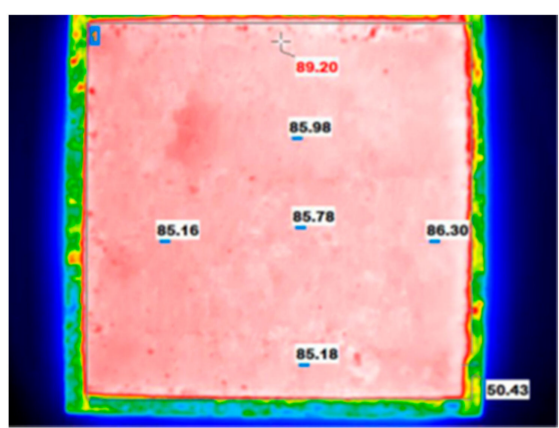

(a) Ortho thermal image

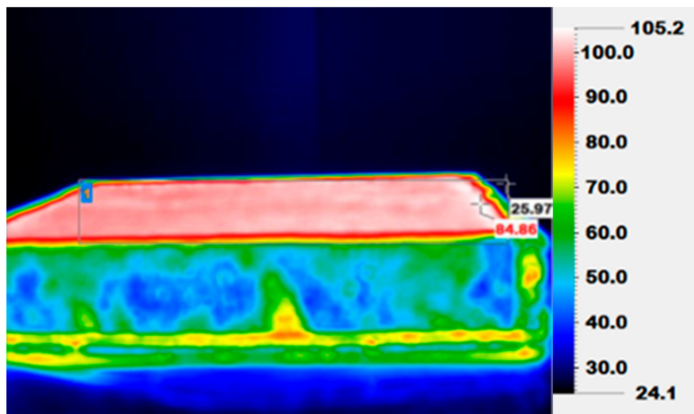

(b) Side thermal image

Figure 9. SMA-graded mixture thermal image $\left({ }^{\circ} \mathrm{C}\right)$.

As shown in Figure $10 \mathrm{a}$, when the center temperature of the PA mixture is $88.59^{\circ} \mathrm{C}$, temperatures at the sides without any significant difference are about $89.12-87.83^{\circ} \mathrm{C}$. A similar trend is also observed for the SMA mixture. In Figure 10b, the internal heat energy (yellow area) area on the PA specimen is more significant $\left(60-80^{\circ} \mathrm{C}\right)$, which means that after adding BOF slag into the PA mixture, it increased the heat preservation effect of $\mathrm{BOF}$ slag with a slower cooling rate, promoting the bonding capacity for the PA mixture.

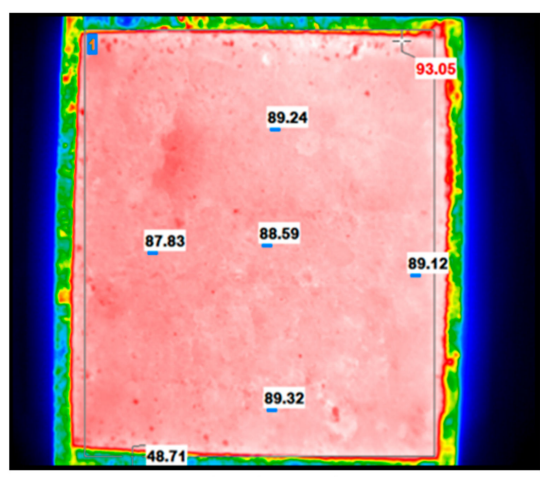

(a) Ortho thermal image

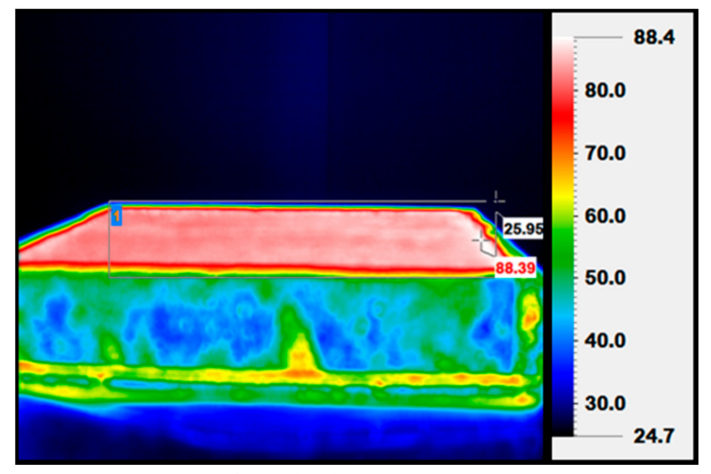

(b) Side thermal image

Figure 10. PA-graded mixture thermal image $\left({ }^{\circ} \mathrm{C}\right)$. 


\section{Conclusions}

This study evaluated the effects of the use of BOF slag as coarse aggregate replacement on the cooling behavior of hot mix asphalt mixtures. From the study test results, the following conclusions can be drawn:

1. The optimum asphalt content of all asphalt mixtures (dense, SMA, and PA) would be decreased in accordance with the increased proportion of BOF slag. BOF slag has a lipophilic property that can absorb asphalt cement, thus reducing the demanded quantity of asphalt.

2. The stability value of asphalt mixture would be increased with the increased BOF slag substitution ratio. Since the coarse aggregate ratio is high in SMA and PA-graded, and BOF slag was substituted for the coarse aggregate, the stability value of asphalt mixture also increased.

3. The VMA value of asphalt mixture would be decreased with the increased BOF slag substitution ratio; the VMA value of PA-graded mixture is lower than those of the dense and SMA-graded ones. BOF slag has porous properties, and asphalt cement can easily permeate into the aggregate and result in the decreased VMA value. Thus, the VMA value can be used to examine whether or not the optimum amount of asphalt has deviated from the others.

4. In order to avoid breakage and degradation of aggregate during the mixing process, BOF slag replacement of $60 \%$ was the optimum substitution for the dense mixture. The replacement of $40 \%$ of BOF slag was the optimum substitution for SMA and PA mixtures.

5. After cooling the dense mixture for about $100 \mathrm{~min}$, the temperature tended to be moderated, which showed that the cooling and heat dissipation was gradually completed. However, after cooling, the SMA and PA-graded mixtures for $120 \mathrm{~min}$, the temperature tended to be moderated, which showed that SMA and PA-graded mixtures have better temperature preservation effectiveness.

6. The voids distribution of the dense mixture was not uniform, and the thermal energy temperature was inconsistent as well. The void distribution of SMA and PA-graded mixtures were more uniform than that of the dense mixture, maintaining the heat energy with a small heat dissipation rate in the cooling phase.

7. The temperatures increased as the BOF slag content increased at the same cooling time. The SMA and PA mixtures with higher BOF slag held the heat better than those containing less BOF slag. Mixtures containing BOF slag also required a longer time to lose heat and, thus, require more time for the pavement to open to traffic.

8. The initial temperature of the SMA and PA mixtures with BOF slag was higher than that of the dense mixture. The SMA specimen coarse aggregate particles form a stone-to-stone contact skeleton that transfers thermal energy and increases all of the temperature zones. Asphalt mixtures have higher porosity and contain higher amounts of coarse aggregate, decreasing the thermal conductivity and resulting in a higher temperature.

Acknowledgments: This study is endorsed by the year 2015 Special Research Program of the Ministry of Science and Technology (MOST 104-2221-E-366-007), Taiwan.

Conflicts of Interest: The author declares no conflict of interest.

\section{References}

1. Motz, H.; Geiseler, J. Products of steel slag an opportunity to save natural resources. Waste Manag. 2001, 21, 285-293. [CrossRef]

2. Rockliff, D.; Moffett, A.; Thomas, N. Recent developments in the use of steel (BOS) slag aggregates in asphalt mixtures in the UK. In Proceedings of the 4th European Symposium on Performance of Bitumiuous and Hydraulic Materials in Pavement, Nottingham, UK, 11-12 April 2002.

3. Xue, Y.J.; Wu, S.P.; Hou, H.B.; Zha, J. Experimental investigation of basic oxygen furnace slag used as aggregate in asphalt mixture. J. Hazard. Mater. 2006, 138, 261-268. [CrossRef] [PubMed] 
4. Xie, J.; Wua, S.; Lin, J.; Cai, J.; Chen, Z.; Wei, W. Recycling of basic oxygen furnace slag in asphalt mixture: Material characterization \& moisture damage investigation. Constr. Build. Mater. 2012, 36, 467-474.

5. David, W.; Philip, M.; Claudio, L.; Cesare, S.; Valeria, V. The wear of Stone Mastic Asphalt due to slow speed high stress simulated laboratory trafficking. Constr. Build. Mater. 2016, 110, 270-277.

6. Khedmati, M.; Khodaii, A.; Haghshenas, H.F. A study on moisture susceptibility of stone matrix warm mix asphalt. Constr. Build. Mater. 2017, 144, 42-49. [CrossRef]

7. Alvarez, A.E.; Martin, A.E.; Estakhri, C. A review of mix design and evaluation research for permeable friction course mixtures. Constr. Build. Mater. 2011, 25, 1159-1166. [CrossRef]

8. Shirini, B.; Imaninasab, R. Performance evaluation of rubberized and SBS modified porous asphalt mixtures. Constr. Build. Mater. 2016, 107, 165-171. [CrossRef]

9. Federal Highway Administration (FHWA). Reclaimed Asphalt Pavement in Asphalt Mixtures: State of the Practice; Federal Highway Administration (FHWA): Washington, DC, USA, 2011; FHWA-HRt-11-021.

10. Praticò, F.G. A Theoretical and Experimental Study of the Effects on Mixes Added with RAP Caused by Superpave Restricted Zone Violation. Road Mater. Pavement Des. 2004, 5, 73-91. [CrossRef]

11. Shen, D.H.; Wu, C.M.; Du, J.C. Laboratory investigation of basic oxygen furnace slag for substitution of aggregate in porous asphalt mixture. Constr. Build. Mater. 2009, 23, 453-461. [CrossRef]

12. Wu, S.; Xue, Y.; Ye, Q.; Chen, Y. Utilization of steel slag as aggregates for stone mastic asphalt (SMA) mixtures. Build. Environ. 2007, 42, 2580-2585. [CrossRef]

13. Wu, S.; Yang, W.; Xue, Y.; Lin, Z. Design and preparation of steel slag SMA. J. Wuhan Univ. Technol. Mater. Sci. 2003, 18, 86-88.

14. Wu, S.; Qiu, L.; No, J.; Zhang, Y.; Li, B. Investigation of temperature characteristics of recycled hot mix asphalt mixtures. Resour. Conserv. Recycl. 2007, 51, 610-620. [CrossRef]

15. Okamoto, P.; Wu, C.; Tarr, S. Opening of Portland Cement Concrete Pavements to Traffic; Potland Cement Association: New York, USA, 1995; R\&D Serial No. 2019.

16. Cole, L.W.; Okamoto, P.A. Flexural Strength Criteria for Opening Concrete Roadways to Traffic. Transp. Res. Rec. 1995, 1478, 53-61.

17. Huang, L.S.; Lin, D.F. Influence of Cooling Efficiency of Basic Oxygen Furnace Slag Used in Recycled Asphalt Mixtures. Int. J. Pavement Res. Technol. 2011, 4, 347-355.

18. Standard Test Method for Density, Relative Density (Specific Gravity), and Absorption of Coarse Aggregate; ASTM International: West Conshohocken, PA, USA, 2007; ASTM C127-07.

19. Standard Method of Test for Resistance to Degradation of Small-Size Coarse Aggregate by Abrasion and Impact in the Los Angeles Machine, 2nd ed.; ASTM International: West Conshohocken, PA, USA, 2010; AASHTO T 96.

20. Standard Test Method for Determining the Percentage of Fractured Particles in Coarse Aggregate; ASTM International: West Conshohocken, PA, USA, 2006; ASTM D5821-01.

21. Standard Test Method for Flat Particles, Elongated Particles, or Flat and Elongated Particles in Coarse Aggregate; ASTM International: West Conshohocken, PA, USA, 2010; ASTM D4791-10.

22. Standard Method of Test for Specific Gravity of Semi-Solid Asphalt Materials; ASTM International: West Conshohocken, PA, USA, 2009; AASHTO T 228.

23. Standard Method of Test for Direct Shear Test of Soils under Consolidated Drained Conditions; ASTM International: West Conshohocken, PA, USA, 2008; AASHTO T 236.

24. Standard Method of Test for Ductility of Asphalt Materials; ASTM International: West Conshohocken, PA, USA, 2013; AASHTO T 51.

25. Standard Method of Test for Flash and Fire Points by Cleveland Open Cup; ASTM International: West Conshohocken, PA, USA, 2006; AASHTO T 48.

26. Standard Specification for Viscosity-Graded Asphalt Cement; ASTM International: West Conshohocken, PA, USA, 1980; AASHTO M226.

27. Standard Method of Test for Solubility of Bituminous Materials; ASTM International: West Conshohocken, PA, USA, 2014; AASHTO T44.

28. Standard Practice for Viscosity-Temperature Chart for Asphalt Binders; ASTM International: West Conshohocken, PA, USA, 2016; ASTM D2493.

29. Standard Specification for Penetration-Graded Asphalt Cement; ASTM International: West Conshohocken, PA, USA, 1970; AASHTO M 20. 
30. Asphalt Institute. Mix Design Methods on Asphalt Concrete and Other Hot Mix Type, MS-2, 6th ed.; Asphalt Institute: Lexington, KY, USA, 1994.

31. Ma, T.; Zhong, T.; Tang, T.; Huang, X. Design and Evaluation of Heat-Resistant Asphalt Mixture for Permafrost Regions. Int. J. Civ. Eng. 2016, 14, 339-346. [CrossRef]

32. Brown, E.R.; Kandhal, P.S.; Zhang, J. Performance Testing for Hot Mix Asphalt; NCAT Report 01-05; Technology Parkway: Auburn, AL, USA, 2001.

33. Xie, J.; Chen, J.; Wu, S.; Lin, J.; Wei, W. Performance characteristics of asphalt mixture with basic oxygen furnace slag. Constr. Build. Mater. 2013, 38, 796-803. [CrossRef]

34. Smith, M.; Coley, K.S. Treatment of Steel Ladle-Slag to Inhibit Falling and Generate a Reusable Bi-Product. In Proceedings of the 3rd International Symposium on Waste Processing and Recycling in Mineral and Metallurgical Industries, Calgary, AB, Canada, 16-19 August 1998; pp. 165-179.

35. Chen, Z.; Xie, J.; Xiao, Y.; Chen, J.; Wu, S. Characteristics of bonding behavior between basic oxygen furnace slag and asphalt binder. Constr. Build. Mater. 2014, 64, 60-66. [CrossRef]

36. Standard Test Method for Marshall Stability and Flow of Asphalt Mixtures; ASTM International: West Conshohocken, PA, USA, 1998; ASTM D1559-89.

37. Willoughby, K.A.; Mahoney, J.P.; Pierce, L.M.; Uhlmeyer, J.S.; Anderson, K.W. Construction-Related Asphalt Concrete Pavement Temperature and Density Differentials. Transp. Res. Rec. 2000, 1813, 68-76. [CrossRef]

38. Mohajerani, A.; Tanriverdi, Y.; Nguyen, B.T.; Wong, K.K.; Dissanayake, H.N.; Johnson, L.; Whitfield, D.; Thomson, G.; Alqattan, E.; Rezaei, A. Physico-mechanical properties of asphalt concrete incorporated with encapsulated cigarette butts. Constr. Build. Mater. 2017, 153, 69-80. [CrossRef]

(C) 2017 by the author. Licensee MDPI, Basel, Switzerland. This article is an open access article distributed under the terms and conditions of the Creative Commons Attribution (CC BY) license (http:/ / creativecommons.org/licenses/by/4.0/). 